\title{
Papers
}

\section{Prophylactic respiratory physiotherapy after cardiac surgery: systematic review}

Patrick Pasquina, Martin R Tramèr, Bernhard Walder

\begin{abstract}
Objective To assess whether respiratory physiotherapy prevents pulmonary complications after cardiac surgery.

Data sources Searches through Medline, Embase, Cinahl, the Cochrane library, and bibliographies, for randomised trials comparing any type of prophylactic respiratory physiotherapy with another type or no intervention after cardiac surgery, with a follow up of at least two days, and reporting on respiratory outcomes.

Review methods Investigators assessed trial validity independently. Information on study design, population, interventions, and end points was abstracted by one investigator and checked by the others.

Results 18 trials (1457 patients) were identified. Most were of low quality. They tested physical therapy (13 trials), incentive spirometry (eight), continuous positive airway pressure (five), and intermittent positive pressure breathing (three). The maximum follow up was six days. Four trials only had a no intervention control; none showed any significant benefit of physiotherapy. Across all trials and interventions, average values postoperatively were: incidence of atelectasis, 15-98\%; incidence of pneumonia, 0-20\%; partial pressure of arterial oxygen per inspired oxygen fraction, 212-329 mm Hg; vital capacity, $37-72 \%$ of preoperative values; and forced expiratory volume in one second, $34-72 \%$. No intervention showed superiority for any end point. For the most labour intensive intervention, continuous positive airway pressure, the average cost of labour for each patient day was $€ 27$ ( $£ 19 ; \$ 32)$.

Conclusions The usefulness of respiratory physiotherapy for the prevention of pulmonary complications after cardiac surgery remains unproved. Large randomised trials are needed with no intervention controls, clinically relevant end points, and reasonable follow up periods.
\end{abstract}

\section{Introduction}

Pulmonary complications after cardiac surgery prolong hospital stay and increase healthcare costs. ${ }^{1}$ We performed a systematic review to determine to what extent respiratory physiotherapy prevents such complications, and the best type of physiotherapy intervention.

We chose the setting of cardiac surgery for three reasons. Firstly, patients are prone to pulmonary complications after surgery; up to $65 \%$ of patients may have an atelectasis, and 3\% may develop pneumonia.. ${ }^{23}$ Secondly, the prevalence of cardiac surgery is high; around 110 per 100000 population annually in the Western world. ${ }^{4}$ Thirdly, the extra costs of pulmonary complications after cardiac surgery exceed €28 000 (£19 000; $\$ 32000$ ) for each patient. ${ }^{5}$

\section{Methods}

\section{Search strategy}

We carried out an extensive search, with no language restrictions, through Medline, Embase, CINAHL, and the Cochrane controlled trials register using these key words: physical therapy, respiratory therapy, breathing exercise, chest physiotherapy, continuous positive airway pressure, incentive spirometry, intermittent positive pressure breathing, noninvasive pressure support ventilation, noninvasive positive pressure ventilation, bilevel positive airway pressure ventilation, cardiac surgery, cardiac operation, coronary artery bypass grafting, and random. The last search was on 19 February 2003. We checked the bibliographies of retrieved reports and reviews. ${ }^{6-8}$ Not considered were data from abstracts, letters, and animal studies. All main authors of all included studies were contacted.

\section{Inclusion criteria, end points, and definitions}

We included full reports of randomised trials of adults or children who had undergone cardiac surgery. Inclusion criteria included any method of prophylactic respiratory physiotherapy compared with no intervention or with another method of respiratory physiotherapy, and an observation period of at least two days.

The trials also had to assess at least one of four end points: atelectasis, pneumonia, oxygenation (partial pressure of arterial oxygen, with the corresponding fractional inspired oxygen), and pulmonary function (vital capacity or forced expiratory volume in one second). If end points were reported at different time points after surgery, we considered the latest. For atelectasis, pneumonia, and adverse effects we extracted dichotomous data. We checked for cointerventions that may have influenced the efficacy of the physiotherapy ${ }^{9}$ : analgesia, respiratory physical therapy other than the tested intervention, and mobilisation. One investigator (PP) abstracted the data, which were independently cross checked by the others. The investigators independently scored the methodological quality of the included studies..$^{11}$

\section{Data analyses}

To establish the relative efficacy of physiotherapy in the absence of a gold standard intervention, we regarded as the most valid study design comparisons between an active intervention and a no intervention control. Active (head to head) comparisons were of secondary importance.

We estimated the cost of physiotherapy, assuming that one physiotherapist was treating one patient at a time. The cost for purchase or maintenance of equipment was not considered, but 


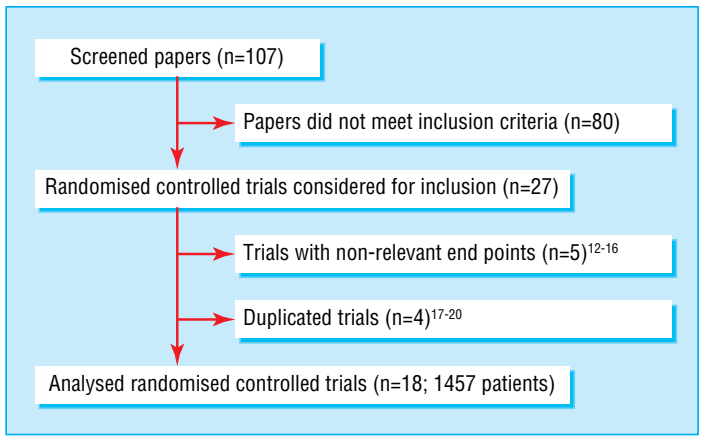

Flow chart of screened, excluded, and analysed papers

we estimated the cost of labour from reported labour time. If no such data were given, we made three assumptions. Firstly, incentive spirometry comprised 10 inspirations, each session lasting five minutes, and a physiotherapist supervised two sessions a day - a total of 10 minutes for each patient day. Secondly, for continuous and intermittent positive pressure breathing, 10 minutes were needed for installation, 10 minutes for adjustments for each hour of therapy, and five minutes for disconnection-a total of 25 minutes for each patient day. Thirdly, for physical therapy, the physiotherapist needed to be present during the entire treatment period except for breathing exercises, when the same assumptions were made as for incentive spirometry. The average salary of a physiotherapist in Europe was estimated at $€ 13 / \mathrm{h}$ (Switzerland $€ 19 / \mathrm{h}$, Belgium $€ 13 / \mathrm{h}$, and France $€ 9 / \mathrm{h}$; data from personal communication in 2003 with physiotherapists working in public hospitals in these countries).

\section{Results}

\section{Trial characteristics}

Of 107 papers screened, 27 randomised controlled trials were eligible for inclusion; nine were subsequently excluded (figure). ${ }^{12-20}$ We analysed data from 18 trials (1457 patients) from nine countries, published between 1978 and 2001 (table 1). ${ }^{21-38}$
Three authors responded to our inquiries ${ }^{23} 24$ : 2 all provided supplementary information, which resulted in one additional trial being identified. ${ }^{22}$ The average group size was 32 patients (range 12-95 patients). Four trials described an adequate randomisation method, two reported on concealment of treatment allocation, and 14 reported on blinding of observers. Three trials used an intention to treat analysis.

Thirteen trials tested 11 different physical therapy regimens; incentive spirometry $(n=8)$, continuous positive airway pressure $(n=5)$, intermittent positive pressure breathing $(n=3)$, and blow bottles $(n=2)$. Cointerventions were used in most trials but adequately described in only four. One trial studied children, one trial studied children and adults, and 16 trials studied adults. Average length of stay in the intensive care unit was 2 to 2.8 days and in the hospital was 7.5 to 13 days.

\section{Active intervention versus no intervention control}

Four trials had a no intervention control..$^{22} 28335$ They tested three physical therapy regimens; deep breathing, deep breathing and cough, and deep breathing and costal expansion exercises. Two also tested incentive spirometry. ${ }^{33}$ We found no evidence of superiority of any active intervention for the end points.

\section{Head to head comparisons}

Atelectasis

Overall, 14 trials (1266 patients) reported on the incidence of atelectasis (table 2 ). One study (44 children) found a significantly lower incidence when less intensive physical therapy was compared with more intensive physical therapy. ${ }^{36}$

\section{Pneumonia}

Nine trials (942 patients) reported on the incidence of pneumonia (table 2). No statistically significant differences were evident.

\section{Oxygenation}

Ten trials (752 patients) reported on partial pressure of arterial oxygen per inspired oxygen fraction (table 3). One trial (58

Table 1 Numbers of patients receiving prophylactic physiotherapy by method in included studies (continued on next page)

\begin{tabular}{|c|c|c|c|c|c|c|}
\hline Study & Incentive spirometry & $\begin{array}{l}\text { Continuous positive } \\
\text { airway pressure }\end{array}$ & Physical therapy & $\begin{array}{l}\text { Intermittent positive pressure } \\
\text { breathing }\end{array}$ & Other & None \\
\hline Westerdahl et al $2001^{21}$ & - & - & 32 & - & $36^{\star}, 30 \dagger$ & - \\
\hline De Charmoy and Eales $2000^{22}$ & - & - & 16 & - & - & 14 \\
\hline Matte et al $2000^{23}$ & 30 & 33 & - & - & $33 \ddagger$ & - \\
\hline Crowe and Bradley $1997^{24}$ & 90 & - & 95 & - & - & - \\
\hline Johnson et al $1996^{25}$ & - & - & $41,34 \S$ & - & - & - \\
\hline Johnson et al $1995^{26}$ & - & - & $48,49 \S$ & - & - & - \\
\hline Richter Larsen et al $1995^{27}$ & - & - & 22 & - & 22 2थ, 22† & - \\
\hline Stiller et al $1994^{28}$ & - & - & $40,40 \S$ & - & - & 40 \\
\hline Jousela et al $1994^{29}$ & - & 15 & 15 & - & - & - \\
\hline Ingwersen et al $1993^{30}$ & - & 17 & - & - & 18ף, 20† & - \\
\hline Oikkonen et al $1991^{31}$ & 26 & - & - & 26 & - & - \\
\hline Pinilla et al $1990^{32}$ & - & 32 & 26 & - & - & - \\
\hline Jenkins et al $1989^{33}$ & 38 & - & 35 & - & - & 37 \\
\hline Stock et al $1984^{34}$ & 12 & 13 & 13 & - & - & - \\
\hline Dull and Dull $1983^{35}$ & 17 & - & 16 & - & - & 16 \\
\hline Reines et al $1982^{36}$ & - & - & $25,19 \S$ & - & - & - \\
\hline Gale and Sanders $1980^{37}$ & 52 & - & - & 57 & - & - \\
\hline Iverson et al $1978^{38}$ & 58 & - & - & 42 & $45^{\star}$ & - \\
\hline
\end{tabular}


Table 1 End points and time of evaluation after surgery in included studies (continued from previous page)

\begin{tabular}{|c|c|c|c|c|c|}
\hline \multirow[b]{2}{*}{ Study } & \multicolumn{4}{|c|}{ End points } & \multirow[b]{2}{*}{ Evaluation (days) postoperatively } \\
\hline & Atelectasis & Pneumonia & $\mathrm{PaO}_{2} / \mathrm{FiO}_{2}$ & Pulmonary function & \\
\hline Westerdahl et al $2001^{21}$ & Yes & - & - & Yes & 4 \\
\hline De Charmoy and Eales $2000^{22}$ & Yes $^{*}$ & Yes & Yes & - & 4 \\
\hline Matte et al $2000^{23}$ & Yes & Yes & Yes & Yes & 2 \\
\hline Crowe and Bradley $1997^{24}$ & Yes & Yes & - & Yes & 4 \\
\hline Johnson et al $1996^{25}$ & Yes & Yes & - & Yes & 6 \\
\hline Johnson et al $1995^{26}$ & Yes $^{*}$ & Yes & - & Yes & 6 \\
\hline Richter Larsen et al $1995^{27}$ & Yes & - & Yes & Yes & 2 \\
\hline Stiller et al $1994^{28}$ & Yes & Yes & Yes & - & 4 \\
\hline Jousela et al $1994^{29}$ & Yes & - & Yes & - & 2 \\
\hline Ingwersen et al $1993^{30}$ & - & - & Yes & Yes & 3 \\
\hline Oikkonen et al $1991^{31}$ & Yes & - & - & Yes & 3 \\
\hline Pinilla et al $1990^{32}$ & Yes & - & Yes & - & 2 \\
\hline Jenkins et al $1989^{33}$ & Yes & Yes & Yes & Yes & 4 \\
\hline Stock et al $1984^{34}$ & Yes & - & Yes & Yes & 4 \\
\hline Dull and Dull $1983^{35}$ & - & - & - & Yes & 3 \\
\hline Reines et al $1982^{36}$ & Yes & Yes & - & - & 3 \\
\hline Gale and Sanders $1980^{37}$ & Yes & - & Yes & - & 3 \\
\hline Iverson et al $1978^{38}$ & Yes & Yes & - & - & 3 \\
\hline
\end{tabular}

$\mathrm{PaO}_{2}=$ arterial oxygen partial pressure; $\mathrm{FiO}_{2}=$ fractional inspired oxygen.

*Not reported in dichotomous form.

Methodological quality of included studies

\begin{tabular}{|c|c|c|c|c|c|c|c|}
\hline \multirow[b]{2}{*}{ Study } & \multicolumn{4}{|c|}{ Quality assessment of trials } & \multicolumn{3}{|c|}{ Cointerventions $\Uparrow$} \\
\hline & Randomisation* & $\begin{array}{l}\text { Concealment of } \\
\text { allocationt }\end{array}$ & Blindingf & Follow up§ & Analgesia & $\begin{array}{c}\text { Additional } \\
\text { physical therapy }\end{array}$ & Mobilisation \\
\hline Westerdahl et al $2001^{21}$ & 1 & 1 & 1 & 1 & - & 1 & 1 \\
\hline De Charmoy and Eales $2000^{22}$ & 1 & 0 & 1 & 1 & - & - & 1 \\
\hline Matte et al $2000^{23}$ & 1 & 0 & 1 & 1 & 1 & 1 & 0 \\
\hline Crowe and Bradley $1997^{24}$ & 2 & 0 & 1 & 1 & - & 1 & 1 \\
\hline Johnson et al $1996^{25}$ & 1 & 0 & 1 & 2 & 2 & - & 2 \\
\hline Johnson et al $1995^{26}$ & 1 & 0 & 1 & 2 & 2 & - & 1 \\
\hline Richter Larsen et al $1995^{27}$ & 1 & 0 & 1 & 1 & - & 1 & 1 \\
\hline Stiller et al $1994^{28}$ & 2 & 0 & 1 & 1 & - & - & 1 \\
\hline Jousela et al $1994^{29}$ & 1 & 1 & 0 & 0 & 0 & 0 & - \\
\hline Ingwersen et al $1993^{30}$ & 1 & 0 & 1 & 1 & - & 1 & 0 \\
\hline Oikkonen et al $1991^{31}$ & 1 & 0 & 1 & 1 & - & 2 & - \\
\hline Pinilla et al $1990^{32}$ & 2 & 0 & 1 & 1 & 0 & 0 & - \\
\hline Jenkins et al $1989^{33}$ & 1 & 0 & 1 & 1 & 0 & - & 2 \\
\hline Stock et al $1984^{34}$ & 2 & 0 & 1 & 0 & 1 & - & - \\
\hline Dull and Dull $1983^{35}$ & 1 & 0 & 0 & 2 & - & 1 & 1 \\
\hline Reines et al $1982^{36}$ & 1 & 0 & 1 & 1 & - & - & - \\
\hline Gale and Sanders $1980^{37}$ & 1 & 0 & 0 & 0 & 1 & - & - \\
\hline Iverson et al $1978^{38}$ & $0^{\star \star}$ & 0 & 0 & 0 & - & 1 & - \\
\hline
\end{tabular}

${ }^{*} 0=$ none or pseudorandomisation; $1=y e s$, not specified; $2=y e s$, and adequate.

†0=none; $1=$ yes.

$\ddagger$ Results for observer only as scores for patient or provider of intervention were zero for trials.

$\S 0=$ none reported; 1 reported; data not analysed according to intention to treat; 2; reported; data analysed according to intention to treat.

१0=Not specified; $1=$ not controlled; $2=$ controlled.

${ }^{*}$ According to patient's hospital number.

patients) found a significant increase with continuous positive airway pressure compared with physical therapy. ${ }^{32}$

\section{Pulmonary function}

Overall, 11 trials (921 patients) reported on vital capacity and eight trials (748 patients) reported on forced expiratory volume in one second (table 3). One trial (96 patients) found a significant increase in both with both continuous positive airway pressure and non-invasive ventilation compared with incentive spirometry. ${ }^{23}$

\section{Adverse effects}

Four trials provided dichotomous data on adverse effects; gastric distension in $2-10 \%$ of patients and nausea in $0-12 \%$ of patients. ${ }^{25} 293238$ Inconvenience of the mask was reported in 43\% of patients receiving continuous positive airway pressure. ${ }^{29} 32$ During physical therapy, $4 \%$ of patients had a percutaneous capillary oxygen saturation of less than $90 \%$ and $1 \%$ of patients had tachycardia. ${ }^{25}$ Eleven trials did not mention any adverse effects, and none were observed in two trials. ${ }^{24}$

\section{Cost estimation}

The median time patients spent receiving physiotherapy was 80 minutes (range 20-120 minutes) for incentive spirometry, 480 minutes (70 to 720 minutes) for continuous positive airway pressure, 80 minutes ( 80 to 120 minutes) for intermittent positive pressure breathing, and 120 minutes (data from one trial only) for physical therapy. ${ }^{23}$ 29-32 343738 Physiotherapy lasted on average 
Table 2 Incidence (percentage) of atelectasis and pneumonia in included studies

\begin{tabular}{|c|c|c|c|c|c|c|}
\hline \multirow[b]{2}{*}{ Study } & \multicolumn{6}{|c|}{ Prophylactic physiotherapy } \\
\hline & Incentive spirometry & $\begin{array}{l}\text { Continuous positive } \\
\text { airway pressure }\end{array}$ & Physical therapy & $\begin{array}{l}\text { Intermittent positive } \\
\text { pressure breathing }\end{array}$ & Other & None \\
\hline \multicolumn{7}{|l|}{ Atelectasis: } \\
\hline Westerdahl et al $2001^{21}$ & - & - & 59 & - & $69^{\star}, 57 \dagger$ & - \\
\hline Matte et al $2000^{23}$ & 30 & 15 & - & - & $15 \ddagger$ & - \\
\hline Crowe and Bradley $1997^{24}$ & 33 & - & 23 & - & - & - \\
\hline Johnson et al $1996^{25}$ & - & - & $34,35 \S$ & - & - & - \\
\hline Richter Larsen et al $1995^{27}$ & - & - & 93 & - & 95ף, 90† & - \\
\hline Stiller et al $1994^{28}$ & - & - & $98,94 \S$ & - & - & 92 \\
\hline Jousela et al $1994^{29}$ & - & 53 & 47 & - & - & - \\
\hline Oikkonen et al $1991^{31}$ & 52 & - & - & 43 & - & - \\
\hline Pinilla et al $1990^{32}$ & - & 94 & 81 & - & - & - \\
\hline Jenkins et al $1989^{33}$ & 61 & - & 53 & - & - & 65 \\
\hline Stock et al $1984^{34}$ & 92 & 67 & 92 & - & - & - \\
\hline Reines et al $1982^{36}$ & - & - & $32,68 \S^{\star \star}$ & - & - & - \\
\hline Gale and Sanders $1980^{37}$ & 65 & - & - & 70 & - & - \\
\hline Iverson et al $1978^{38}$ & 60 & - & - & 55 & $40^{*}$ & - \\
\hline \multicolumn{7}{|l|}{ Pneumonia: } \\
\hline De Charmoy and Eales $2000^{22}$ & - & - & 0 & - & - & 0 \\
\hline Matte et al $2000^{23}$ & 3 & 3 & - & - & $0 \neq$ & - \\
\hline Crowe and Bradley $1997^{24}$ & 9 & - & 11 & - & - & - \\
\hline Johnson et al $1996^{25}$ & - & - & $5,6 \S$ & - & - & - \\
\hline Johnson et al $1995^{26}$ & - & - & $17,20 \S$ & - & - & - \\
\hline Stiller et al $1994^{28}$ & - & - & $10,3 \S$ & - & - & 3 \\
\hline Jenkins et al $1989^{33}$ & 5 & - & 11 & - & - & 14 \\
\hline Reines et al $1982^{36}$ & - & - & $8,5 \S$ & - & - & - \\
\hline Iverson et al $1978^{38}$ & 0 & - & - & 2 & $0^{\star}$ & - \\
\hline
\end{tabular}

*Blow bottles.

†Inspiratory resistance and positive expiratory pressure mask.

łNon-invasive ventilatory support with bilevel positive airway pressure.

$\S$ Less intensive physical therapy, more intensive physical therapy.

१Positive expiratory pressure mask.

**Statistically significant differences between types of physiotherapy, as reported in original trials.

0.3 to 5 days. ${ }^{21} 22282931-3437$ The average daily cost of labour for each patient was $€ 6$ for incentive spirometry, $€ 10$ for physical therapy, €20 for intermittent positive pressure breathing, and $€ 27$ for continuous positive airway pressure (table 4).

\section{Discussion}

Evidence is lacking as to whether prophylactic respiratory physiotherapy prevents pulmonary complications after cardiac surgery. Two published systematic reviews examined the relation between respiratory physiotherapy and outcome after different operations, but they obtained conflicting results. One found benefits from incentive spirometry and deep breathing exercises after upper abdominal surgery, but pooled data came from different end points such as atelectasis and pulmonary infiltrates or consolidation. ${ }^{39}$ The other review found incentive spirometry to be of no benefit after cardiac and upper abdominal surgery. ${ }^{8}$ Again, data were combined from trials with a variety of different end points. Our conclusions reflect more uncertainty, showing several limitations in the original trials. These limitations are the main weakness of our systematic review.

\section{Limitations}

Eighteen trials tested eight regimens of prophylactic respiratory physiotherapy. This variety, which is not dissimilar to other settings, may be due to the lack of a gold standard method for respiratory physiotherapy. ${ }^{40}$ If ethically acceptable, the best comparator is then a placebo or, as in the physiotherapy setting, a no intervention control. ${ }^{41}$ Four trials only had a no intervention control group, and each tested a different method of physiotherapy.2 283335 Based on these trials, it was therefore difficult for us to determine the efficacy of different methods of respiratory physiotherapy.

On average the quality of the trials was low. Only a minority reported on an appropriate method of randomisation or on concealment of allocation, although bad reporting may not mean bad practice. In only a few trials was the follow up of patients adequately reported and data analysed according to intention to treat. One inherent problem of trials in this setting is that at best the observer can be blinded. Over two thirds of the trials attempted to blind the observers. We do not know if trials of better quality would have reached different conclusions.

Practical management of physiotherapy was inconsistent. For example, the reported duration of daily continuous positive airway pressure varied by a factor of 10 . Inconsistency suggests that there is uncertainty about how each method should be applied and how frequently.

For most end points there was variability in event rates. The average incidence of pneumonia was 0-20\%. ${ }^{23} 26{ }^{38}$ Two reasons may explain this variability. Firstly, there were no uniform definitions of pneumonia; one study used established criteria only. ${ }^{26}$ Secondly, most trials were of limited size. Only two studies included groups of more than 50 patients. ${ }^{24}{ }^{37}$ In small trials anything can happen by random chance. ${ }^{42}$

The longest observation period was six days. This may be too short in which to identify all respiratory complications. Nosocomial pneumonia, for instance, occurs on average eight days after cardiac surgery. ${ }^{43}$

In large randomised controlled trials, cointerventions are usually balanced between the groups. In small trials, however, we cannot exclude bias related to an imbalance of cointerventions. 
Table 3 Postoperative partial pressure of oxygen and fractional inspired oxygen $\left(\mathrm{PaO}_{2} / \mathrm{FiO}_{2}\right)$, vital capacity, and forced expiratory volume in one second in included studies. Values are means (standard deviations) unless stated otherwise

\begin{tabular}{|c|c|c|c|c|c|c|}
\hline \multirow[b]{2}{*}{ Study } & \multicolumn{6}{|c|}{ Prophylactic physiotherapy } \\
\hline & $\begin{array}{l}\text { Incentive } \\
\text { spirometry }\end{array}$ & $\begin{array}{l}\text { Continuous positive } \\
\text { airway pressure }\end{array}$ & Physical therapy & $\begin{array}{l}\text { Intermittent positive } \\
\text { pressure breathing }\end{array}$ & Other & None \\
\hline \multicolumn{7}{|l|}{$\mathrm{PaO}_{2} / \mathrm{FiO}_{2}(\mathrm{~mm} \mathrm{Hg}):$} \\
\hline De Charmoy and Eales $2000^{22}$ & & & $287(67)$ & & & $281(44)$ \\
\hline Matte et al $2000^{23}$ & $300(43)$ & $314(43)$ & & & $329(57)^{\star}$ & \\
\hline Richter Larsen et al $1995^{27}$ & & & $305 \dagger$ & & $289 \dagger \ddagger, 291+\S$ & \\
\hline Stiller et al $1994^{28}$ & & & 298 (35), 298 (38)ף & & & $307(42)$ \\
\hline Jousela et al $1994^{29}$ & & $270(39)$ & $287(37)$ & & & \\
\hline Ingwersen et al $1993^{30}$ & & $314 \dagger$ & & & $317 \dagger \ddagger, 325 \dagger \S$ & \\
\hline Pinilla et al $1990^{32}$ & & $234(57)^{\star *}$ & $212(56)^{* *}$ & & & \\
\hline Jenkins et al $1989^{33}$ & $305(38)$ & & $310(43)$ & & & $300(43)$ \\
\hline Stock et al $1984^{34}$ & $233(43)$ & $235(42)$ & $248(53)$ & & & \\
\hline Gale and Sanders $1980^{37}$ & $289(65)$ & & & $283(57)$ & & \\
\hline \multicolumn{7}{|l|}{ Vital capacity (ml): } \\
\hline Westerdahl et al $2001^{21}$ & & & $2400(500)$ & & $2600(600) \dagger \dagger, 2600(600) \S$ & \\
\hline Matte et al $2000^{23}$ & $1332(398)^{* *}$ & $1670(670)^{\star *}$ & & & $1759(522)^{\star \star *}$ & \\
\hline Crowe and Bradley $1997^{24}$ & $1547 \dagger$ & & $1372 \dagger$ & & & \\
\hline Johnson et al $1996^{25}$ & & & 2100 (1000), 1700 (500)ף & & & \\
\hline Johnson et al $1995^{26}$ & & & 2700 (700), 2800 (500)ף & & & \\
\hline Richter Larsen et al $1995^{27}$ & & & 47 㧊 & & 45 㧊, 41§㧊 & \\
\hline Ingwersen et al $1993^{30}$ & & 45 㧊 & & & $38 \ddagger \ddagger \ddagger, 42 \S \neq \ddagger$ & \\
\hline Oikkonen et al $1991^{31}$ & $1441(114)$ & & & $1713(170)$ & & \\
\hline Jenkins et al $1989^{33}$ & $2200(600)$ & & $2100(600)$ & & & $2200(600)$ \\
\hline Stock et al $1984^{34}$ & $1812(142)$ & $1409(154)$ & $1444(171)$ & & & \\
\hline Dull and Dull $1983^{35}$ & $1980(510)$ & & $1700(350)$ & & & $2045(790)$ \\
\hline \multicolumn{7}{|c|}{ Forced expiratory volume in one second $(\mathrm{ml})$ : } \\
\hline Westerdahl et al $2001^{21}$ & & & $1800(400)$ & & $1900(400)$ ††, $1900(400) \S$ & \\
\hline Matte et al $2000^{23}$ & $884(258)^{* *}$ & $1067(256)^{\star \star *}$ & & & $1097(369)^{\star \star *}$ & \\
\hline Crowe and Bradley $1997^{24}$ & $1045(270)$ & & $990(270)$ & & & \\
\hline Johnson et al $1996^{25}$ & & & 1600 (800), $1300(400)$ ி & & & \\
\hline Johnson et al $1995^{26}$ & & & 1800 (500), $1700(500)$ 凡 & & & \\
\hline Jenkins et al $1989^{33}$ & $1700(450)$ & & $1700(350)$ & & & $1700(450)$ \\
\hline Stock et al $1984^{34}$ & 1497 (99) & 1138 (135) & $1197(152)$ & & & \\
\hline Dull and Dull $1983^{35}$ & $1480(435)$ & & $1320(320)$ & & & $1430(520)$ \\
\hline
\end{tabular}

${ }^{*}$ Non-invasive ventilatory support with bilevel positive airway pressure.

†Standard deviation not available.

$\Varangle$ Positive expiratory pressure mask.

§Inspiratory resistance and positive expiratory pressure mask.

ILess intensive physical therapy, more intensive physical therapy.

${ }^{* \star}$ Statistically significant differences between interventions, as reported in original trials.

††Blow bottles.

$\ddagger \neq V i t a l$ capacity presented as percentage of preoperative volume.

Table 4 Estimated time and costs of labour for physiotherapists using different methods of prophylactic respiratory physiotherapy in patients after cardiac surgery

Prophylactic physiotherapy

\begin{tabular}{lccc}
\cline { 2 - 4 } & Incentive spirometry & Continuous positive airway pressure & Physical therapy \\
\hline $\begin{array}{l}\text { Median of average labour time per patient } \\
\text { and per day (min) }\end{array}$ & 30 & 120 & 45 \\
\hline $\begin{array}{l}\text { Estimated average labour cost per patient } \\
\text { and per day (Euros) }\end{array}$ & 6 & 27 & 10 \\
\hline
\end{tabular}

${ }^{*}$ Estimation, using assumptions as reported in methods section.

Sixteen of the 18 trials had less than 50 patients in each group, thus cointerventions may have affected the efficacy of physiotherapy. Method and intensity of postoperative analgesia may have an impact on pulmonary function. ${ }^{44}$ Early mobilisation may also have an effect on outcome. Only three trials adequately controlled for concomitant analgesia or mobilisation. ${ }^{25} 2633$

\section{Implications}

Because there was no evidence of any benefit from respiratory physiotherapy, we were unable to determine the cost incurred to generate one patient who would profit from an intervention compared with doing nothing. If there is no benefit, there are only costs, and these are not negligible in this context.

We thank Daniel Haake (medical libraries, Centre Medical Universitaire, Geneva University) for his help in searching electronic databases, and Kathy Stiller, Jean Crowe, and Pascal Matte who provided additional information. Contributors: PP initiated, designed, and organised the study, and extracted and analysed the data. He will act as guarantor for the paper. MRT designed the study, cross checked the studies, and analysed the data. BW initiated and designed the study, cross checked the studies, and analysed the data.

Funding: MRT is a beneficiary of a PROSPER grant from the Swiss National Science Foundation (No 3233-051939.97/2). 


\section{What is already known on this topic}

Prophylactic respiratory physiotherapy after cardiac surgery is widely used

It is thought to reduce the risk of pulmonary complications such as pneumonia or atelectasis

\section{What this study adds}

Evidence is lacking on benefit from any method of prophylactic respiratory physiotherapy after cardiac surgery

It is likely that there are adverse effects and costs only

Competing interests: None declared.

Ethical approval: None required.

1 Lawrence VA, Hilsenbeck SG, Mulrow CD, Dhanda R, Sapp J, Page CP. Incidence and hospital stay for cardiac and pulmonary complications after abdominal surgery. J Gen Intern Med 1995;10:671-8.

2 Jain U, Rao TL, Kumar P, Kleinman BS, Belusko RJ, Kanuri DP, et al. Radiographic pulmonary abnormalities after different types of cardiac surgery.J Cardiothorac Vasc Anesth 1991;5:592-5.

3 Carrel TP, Eisinger E, Vogt M, Turina MI. Pneumonia after cardiac surgery is predictable by tracheal aspirates but cannot be prevented by prolonged antibiotic prophylaxis. Ann Thorac Surg 2001;72:143-8.

4 Pangano DT Perioperative cardiac morbidity. Anesthesiology 1990;72:153-84.

5 Taylor GJ, Mikell FL, Moses HW, Dove JT, Katholi RE, Malik SA, et al. Determinants of hospital charges for coronary artery bypass surgery: the economic consequences of postoperative complications. Am J Cardiol 1990;65:309-13.

6 Thornlow DK. Is chest physiotherapy necessary after cardiac surgery? Crit Care Nurse 1995;47:39-46.

7 Denehy L, Berney S. The use of positive pressure devices by physiotherapists. Eur Respir J2001;17:821-9.

8 Overend TJ, Anderson CM, Lucy SD, Bhatia C, Jonsson BI, Timmermans C. The effect of incentive spirometry on postoperative pulmonary complications: a systematic review. Chest 2001;120:971-8.

9 Boldt J, Thaler E, Lehmann A, Papsdorf M, Isgro F. Pain management in cardiac surgery patients: comparison between standard therapy and patient-controlled analgesia regimen. J Cardiothorac Vasc Anesth 1998;12:654-8.

10 Juni P, Witschi A, Bloch R, Egger M. The hazards of scoring the quality of clinical trials or meta-analysis. JAMA 1999;282:1054-60.

11 Juni P, Altman DG, Egger M. Systematic reviews in health care: assessing the quality of controlled clinical trials. BMJ 2001;323:42-6.

12 Ruoff M, Koch M, Buhler A, Lindner KH, Brinkmann A, Radermacher P, et al. Effect of CPAP-application via nasal mask and mouth-piece on gas exchange and respiratory mechanics after cardiac surgery. Clin Intensive Care 2000;11:29-34

13 Oulton JL, Hobbs GM, Hicken P. Incentive breathing devices and chest physiopathy: a controlled therapy. Can J Surg 1981;24:638-40.

14 Vraciu JK, Vraciu RA. Effectiveness of breathing exercises in preventing pulmonary complications following open heart surgery. Phys Ther 1977:57:1367-71.

15 Thomas AN, Ryan JP, Doran BR, Pollard BJ. Nasal CPAP after coronary artery surgery. Anaesthesia 1992;47:316-9.

16 Krastins I, Corey ML, McLeod A, Edmonds J, Levison H, Moes F. An evaluation of incentive spirometry in the management of pulmonary complications after cardiac surgery in a pediatric population. Crit Care Med 1982;10:525-8

17 Jenkins SC, Soutar SA, Loukota JM, Johnson LC, Moxham J. A comparison of breathing exercises, incentive spirometry and mobilisation after coronary artery surgery. Physiother Theory Pract 1990;6:117-26.

18 Larsen KR, Ingwersen U, Bertelsen MT, Kiil-Nielsen K, Laub MS, Bach KS, et al Prevention of postoperative pulmonary complications after heart-lung surgery. Comparison of 3 different mask physiotherapy regimens. Ugeskr Laeger 1994:156:5689-92.

19 Stiller K, Montarello J, Wallace M, Daff M, Grant R, et al. Are breathing and coughing exercises necessary after coronary artery surgery? Physiother Theory Pract 1994:10:14352.

20 Larsen KR, Ingwersen U, Thode S, Jakobsen SH. Mask physiotherapy for prevention of pulmonary complications after heart surgery. A controlled study. Ugeskr Laeger 1997;159:2096-9.
21 Westerdahl E, Lindmark B, Almoren SO, Tenling A. Chest physiotherapy after coronary artery bypass graft surgery-a comparison of three different deep breathing techniques. J Rehabil Med 2001;33:79-84.

22 De Charmoy SB, Eales CJ. The role of prophylactic chest physiotherpy after cardiac valvular surgery: is there one? S Afr J Physiother 2000;56:24-8.

23 Matte P, Jacquet L, Van Dyck M, Goenen M. Effects of conventional physiotherapy, continuous positive airway pressure and non-invasive ventilatory support with bilevel positive airway pressure after coronary artery bypass grafting. Acta Anaesthesiol Scand 2000;44:75-81.

24 Crowe JM, Bradley CA. The effectiveness of incentive spirometry with physical therapy for high-risk patients after coronary artery bypass surgery. Phys Ther 1997;77:260-8.

25 Johnson D, Kelm C, Thomson D, Burbridge B, Mayers I. The effect of physical therapy on respiratory complications following cardiac valve surgery. Chest 1996;109:638-44.

26 Johnson D, Kelm C, To T, Hurst T, Naik C, Gulka I, et al. Postoperative physical therapy after coronary artery bypass surgery. Am J Respir Crit Care Med 1995;152:953-8.

27 Richter Larsen K, Ingwersen U, Thode S, Jakobsen S. Mask physiotherapy in patients after heart surgery: a controlled study. Intensive Care Med 1995;21:469-74.

28 Stiller K, Montarello J, Wallace M, Daff M, Grant R, Jenkins S, et al. Efficacy of breathing and coughing exercises in the prevention of pulmonary complications after coronary artery surgery. Chest 1994;105:741-7.

29 Jousela I, Rasanen J, Verkkala K, Lamminen A, Makelainen A, Nikki P. Continuous positive airway pressure

30 Ingwersen UM, Larsen KR, Bertelsen MT, Kiil-Nielsen K, Laub M, Sandermann J, et al. Three different mask physiotherapy regimens for prevention of post-operative pulmonary complications after heart and pulmonary surgery. Intensive Care Med 1993;19:294-8.

31 Oikkonen M, Karjalainen K, Kahara V, Kuosa R, Schavikin L. Comparison of incentive spirometry and intermittent positive pressure breathing after coronary artery bypass graft. Chest 1991;99:60-5.

32 Pinilla JC, Oleniuk FH, Tan L, Rebeyka I, Tanna N, Wilkinson A, et al. Use of a nasal continuous positive airway pressure mask in the treatment of postoperative atelectasis in aortocoronary bypass surgery. Crit Care Med 1990;18:836-40.

33 Jenkins SC, Soutar SA, Loukota JM, Johnson LC, Moxham J. Physiotherapy after coronary artery surgery: are breathing exercises necessary? Thorax 1989;44:634-9.

34 Stock MC, Downs JB, Cooper RB, Lebenson IM, Cleveland J, Weaver DE, et al Comparison of continuous positive airway pressure, incentive spirometry, and Comparison of continuous positive airway pressure, incentive spirom

35 Dull JL, Dull WL. Are maximal inspiratory breathing exercises or incentive spirometry Dull JL, Dull WL. Are maximal inspiratory breathing exercises or incentive spirometry
better than early mobilization after cardiopulmonary bypass? Phys Ther 1983;63:655-9.

36 Reines HD, Sade RM, Bradford BF, Marshall J. Chest physiotherapy fails to preven postoperative atelectasis in children after cardiac surgery. Ann Surg 1982;195:451-5.

37 Gale GD, Sanders DE. Incentive spirometry: its value after cardiac surgery. Can Anaesth Soc J 1980;27:475-80.

38 Iverson LI, Ecker RR, Fox HE, May IA. A comparative study of IPPB, the incentive spirometer, and blow bottles: the prevention of atelectasis following cardiac surgery. Ann Thorac Surg 1978;25:197-200.

39 Thomas JA, McIntosh JM. Are incentive spirometry, intermittent positive pressure breathing, and deep breathing exercises effective in the prevention of postoperative pulmonary complications after upper abdominal surgery? A systematic overview and pulmonary complications after upper
meta-analysis. Phys Ther 1994:74:3-10.

40 Tramèr MR, Reynolds DJ, Moore RA, McQuay HJ. When placebo controlled trials are essential and equivalence trials are inadequate. BMJ 1998;317:875-80

41 Temple R, Ellenberg SS. Placebo-controlled trials and active-control trials in the evaluation of new treatments. Part 1: ethical and scientific issues. Ann Intern Med 2000;133:455-63.

42 Moore RA, Gavaghan D, Tramèr MR, Collins SL, McQuay HJ. Size is everything-large amounts of information are needed to overcome random effects in estimating direction and magnitude of treatment effects. Pain 1998;78:209-16.

43 Leal-Noval SR, Marquez-Vacaro JA, Garcia-Curiel A, Camacho-Larana P, RinconFerrari MD, Ordonez-Fernandez A, et al. Nosocomial pneumonia in patients undergoing heart surgery. Crit Care Med 2000;28:935-40.

44 Hedderich R, Ness TJ. Analgesia for trauma and burns. Crit Care Clin 1999;15:167-84. (Accepted 16 October 2003)

bmj.com 2003;327:1379

Division of Surgical Intensive Care, Department of Anaesthesiology,

Pharmacology and Surgical Intensive Care, Geneva University Hospitals, CH-1211

Geneva 14, Switzerland

Patrick Pasquina physiotherapist

Division of Anaesthesiology, Department of Anaesthesiology, Pharmacology and Surgical Intensive Care, Geneva University Hospitals

Martin R Tramèr staff anaesthetist

Bernhard Walder senior registrar

Correspondence to: P Pasquina Patrick.Pasquina@hcuge.ch 